\title{
Narcissism and Defending Self-Esteem. An Exploratory Study based on Self-characterizations
}

\author{
Guido Veronese ${ }^{1, *}$, Rossella Procaccia ${ }^{2}$, Giovanni M. Ruggiero ${ }^{3}$, Sandra Sassaroli $^{3}$ and \\ Marco Castiglioni ${ }^{1}$
}

${ }^{I}$ Department of Human Sciences, University of Milano-Bicocca, Italy

${ }^{2}$ University e-Campus, Novedrate (LC), Italy

${ }^{3}$ Studi Cognitivi, Psychotherapy School, Milano, Italy

\begin{abstract}
The present qualitative study aims at investigating the role of socio-relational variables in the construction of threats to self-esteem, grandiosity, and relaxation in a non-clinical sample of 35 young university students. The work provides fresh experimental evidence of the structural analogy observed in clinical settings between constructions of threat to self-esteem and grandiose fantasies. We hypothesize that the relational dimension would be more strongly present than either biological or psychological dimensions. The results show that descriptions of relaxation differ significantly from their characterizations of the other two domains. Specifically we found greater continuity and narrative connection between the aspects of threat and grandiosity, while the domain of relaxation showed a more "isolated" pattern.
\end{abstract}

Keywords: Grandiose fantasies, threat to self-esteem, non-pathological narcissism, self-characterzation, qualitative methods.

\section{INTRODUCTION}

As defined by DSM IV-TR [1], the distinctive traits of patients with Narcissistic Personality Disorder (NPD) include grandiose fantasies of power, success and/or superiority; a feeling of entitlement; and an inability to appreciate the successes and good qualities of others [2]. Horowitz [3] suggested that grandiose states are actually a defensive manoeuvre with the function of mitigating feelings of low self-esteem and masking a deep-lying sense of inferiority and shame. Through their grandiose fantasies, narcissists attempt to protect themselves from criticism and humiliation, both of which they experience as intolerable [413]. All narcissistic subjects perceive themselves at some level to be excluded, despised and ostracized $[2,14,15]$.

Veronese and colleaugues [16] reported empirical evidence of an interconnection between grandiose fantasies and fantasies of threats to self-esteem in a study with a nonclinical sample; in contrast, evoking relaxing scenarios has been found to distract subjects from narcissistic contents [17].

The current study was underpinned by a systemicconstructionist perspective, which attributes a primary role to intersubjectivity and social (particularly familial) relations in the origin, development and maintenance of the self and

*Address correspondence to this author at the Department of Human Siences, Univesity of Milano-Bicocca, Piazza dell'Ateneo Nuovo 1, 20126, Milano, Italy; Tel: +39 2 64484800; Fax: +39(0)264484863;

E-mail: guido.veronese@unimib.it identity, whether typical or atypical. In this approach, the relational context is viewed as "complex", including in addition to "traditional" dyadic relationships, interactions among three or more participants [18-23].

The aim of the study was to conduct a qualitative exploration of how narcissistic defensive structures may contribute to increased risk of loss of self-esteem in nonpathological individuals. Specifically, we examined the construct system of a sample of university students, with a view to advancing understanding of non-pathological narcissistic mechanisms and informing theoretical reflection on analogous traits of pathological narcissism [6, 24].

One of the peculiar traits of narcissism, whether in the context of a healthy and balanced personal identity [25] or of a pathological personality type $[2,6]$ is a marked difficulty in building and maintaining significant "warm" relationships with others. Narcissistic individuals' preoccupation with rank and their continuous monitoring of relationships perceived as threatening prevents them from committing to warm relationships or forming strong relational bonds. This also explains why one of the key challenges in psychotherapy with persons affected by NPD is building a satisfactory therapeutic alliance between patient and therapist. The primary outcome of this difficulty in establishing relationships is the tendency to exploit relationships to achieve the narcissist's own ends in cases of non-pathological narcissism, and a self-perpetuating cycle of rupture and repair of the psychotherapist-patient therapeutic alliance in the case of pathological narcissism [26]. Both in 
the case of NPD and in that of non-pathological narcissistic traits, a fear of relationships perceived as threatening appears to have a crucial influence on the construct systems of individuals. Nonetheless, few studies reported in the literature have explored the narcissistic personality from a relational perspective or attempted to explain the relational characteristics of the narcissistic personality [24, 27, 28]. It would almost appear that the relational domain is treated as a superordinate category mediated by individual variables of the psychological, emotional and behavioural kinds [7-9].

Given the theoretical background just outlined, our research aim was to investigate the role of socio-relational variables in the construction of threats to self-esteem, grandiosity, and relaxation. Specifically, we hypothesized that the relational dimension would be more strongly present than either biological or psychological dimensions.

A further aim was to provide fresh experimental evidence, in a non-clinical sample of young university students, of the structural analogy observed in clinical settings between constructions of threat to self-esteem and grandiose fantasies; we also hypothesized that participants' descriptions of relaxation would differ significantly from their characterizations of the other two domains. Specifically we expected that there would be greater continuity and narrative connection between the aspects of threat and grandiosity, and that the domain of relaxation would present a more "isolated" pattern.

Thus, we set out to use qualitative analysis of selfcharacterizations [29], to verify whether, and to what extent, relational aspects prevail over psychological and biological aspects in the defence strategies that individuals normally activate to protect themselves from threats to their selfesteem. In our view, threats themselves are also more relational in nature than psychological and biological. Thus, structural similarities between the threatening and "protective grandiose" contents of the self in individuals' self-characterizations would suggest the hypothesis that a coping strategy of using grandiose fantasies to protect the self from threats to self-esteem is ineffective and counterproductive. We therefore also set out to explore via the self-characterization task whether, as suggested in the literature, relaxation strategies may not represent a valid alternative to the use of the grandiose self in coping with threats to self-esteem.

\section{METHOD}

Instrument and administration procedure

A purposive convenience sample of 35 university students (average age 22.5; sd 3.2) was asked to write a selfcharacterization [30]. In order to protect participants' anonymity and privacy, they were asked to identify themselves with a nickname that did not reveal their true identity. They were given as much time as necessary, in practice between 25 and 45 minutes, to compose their selfdescription.

The specific instructions provided were as follows:

"First of all, please choose a nickname for yourself (for example your initials followed by your date of birth).
Write your nickname on each of the sheets that you are given. Try to choose an "original" nickname to prevent you from being confused with another respondent.

Now, please write a character sketch of yourself, just as if you were the main character in a play. Write it as it might be written by a friend who knew you very intimately, perhaps better than anybody else. Be careful to use the third person. For example, begin by saying " $\mathrm{X}$ (= nickname) is ...".

The task was administered to all participants at one sitting.

\section{Data analysis}

The self-characterization texts were subjected to content analysis. We used the software for textual analysis Atlas-Ti to define the relationships between semantic nodes ascribable to our three preordained families (or clusters) of threat, grandiosity and relaxation and to a further three families of codes predefined on the basis of the bio-psychosocial model [31]. Thus nine families of codes were created in all: the families of biological, psychological and relational codes (dimensions), distributed across three macro-families or domains: threat, grandiosity and relaxation.

Atlas-Ti is a software for the coding and analysis of texts. The analytical procedure involves importing the text, reading it closely, and then selecting words, phrases or paragraphs (quotations) to link to a series of conceptual categories (codes). The data may subsequently be exported to statistical packages such as Spss for the purposes of quantitative investigation. One of the advantages of Atlas-Ti is that aggregate codes, individual codes or citations may be easily retrieved in real time. This function is useful both during the analysis phase and for the purposes of calling up fragments of text for inclusion in the research report. As well as allowing analysis to be conducted rapidly and flexibly, the programme is suited to the treatment and manipulation of large quantities of data. In the present study, after a first "free" coding stage carried out by a researcher whose brief was to stay as closely as possible to the text, the initial codes were classified and relabelled (e.g., "strong self-esteem"; etc..) via inter-judge discussion, and then grouped into three clusters: the first cluster contained all the fragments of text ascribable to a semantic universe of threat to self-esteem, namely descriptions, adjectives or nouns that could be perceived as undermining a positive self-image (e.g., "feels inadequate", etc.); the second cluster was related to the semantic universe of "grandiosity", that is to say, all descriptions that could be read as attempts to defend the self from threat by defining it positively, in terms of selfefficacy, relational success, etc.; the third cluster was made up of nouns, adjectives and descriptive phrases that reflected an attempt on the part of the respondent to relax without invoking either positive or negative definitions of self (e.g., "winds down while painting"). The coders then subdivided each of the three clusters of threat, grandiosity and relaxation into three dimensions: the first grouped together descriptions focusing on the body and physiological states (biological dimension), the second contained references to inner and psycho-emotional experience (psychological dimension), while the third contained fragments of text describing 
respondents' social and relational lives (relational dimension). Finally the coders defined a series of logicalsemantic connections (such as code $\mathrm{A}$ is related to $\mathrm{B}, \mathrm{A}$ is part of B, A causes B, A is a property of B, etc.) among the codes from the three bio-psycho-social dimensions and the three domains of self-description (self under threat, grandiose self and "relaxing" to distance the self from threat).

\section{RESULTS}

The self-characterizations reflected a tendency for individuals to describe themselves predominantly in psychological and relational terms (see Table 1). The tendency to describe the self in terms of the bodily dimension was far more limited (see Fig. 1). The relational dimension was slightly more prominent than the psychological dimension in terms of number of occurrences (quotations) and frequency of codes. References to the biological dimension were far less numerous and frequent. The frequency of psychological and relational codes in the threatening and grandiose domains was almost equal, whereas these domains contained drastically fewer references to the biological dimension.

The domains of threat and grandiosity were characterized by highly similar semantic structures. In both cases, the semantic network of the psychological dimension revolved around the "node" of "self-esteem" (see Figs. 2 \& 3), and that of the socio-relational dimension around nodes concerning significant relationships and themes of social belonging and loneliness.

In contrast, the domain of relaxation was characterized by a completely different semantic structure and selfdescriptive modes to the other two domains: the prevalent meanings were those related to the sphere of religion and self-liberating practices, which allowed respondents to "detach" from the issues of belonging and self-esteem. Thus this dimension appeared to be totally independent of those of threat and grandiosity. The attempts to relax described in the self-characterizations were never relational in nature (see Fig. 3) [32].

Thus, in general, the threatening and grandiose descriptions formed similar semantic networks, as though personal identity were in constant and unstable equilibrium between a threatened self and a grandiose form of narcissistic defence. It appears that the more individuals try to defend themselves from threats to their identity by raising the shield of narcissistic grandiosity, the more the self feels threatened by the failure of this strategy of "positive selfdescription". Subjects become trapped in a vicious cycle that does not allow them to distance themselves from the continuous battle between their need to define themselves positively and humiliating attacks on their self-esteem [7-9].

Table 1. Frequency of biological, psychological and relational codes in the domains of grandiosity, relaxation and threat.

\begin{tabular}{|c|c|c|c|c|}
\hline Domain/Dimension & Grandiosity & Relaxation & Threat & 11 \\
\hline \hline Biological & 10 & 3 & 41 & 24 \\
\hline Psychological & 44 & 5 & 50 & 90 \\
\hline Relational & 48 & 0 & 102 & 212 \\
\hline Tot. & 102 & 8 & & 98 \\
\hline
\end{tabular}
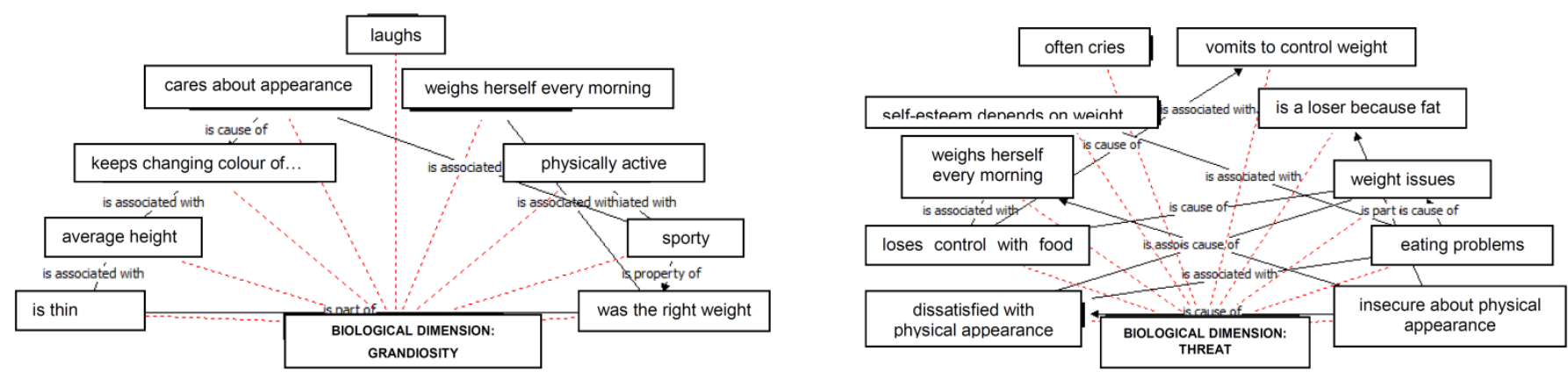

relaxes when listening to music cries to get relief from stress 

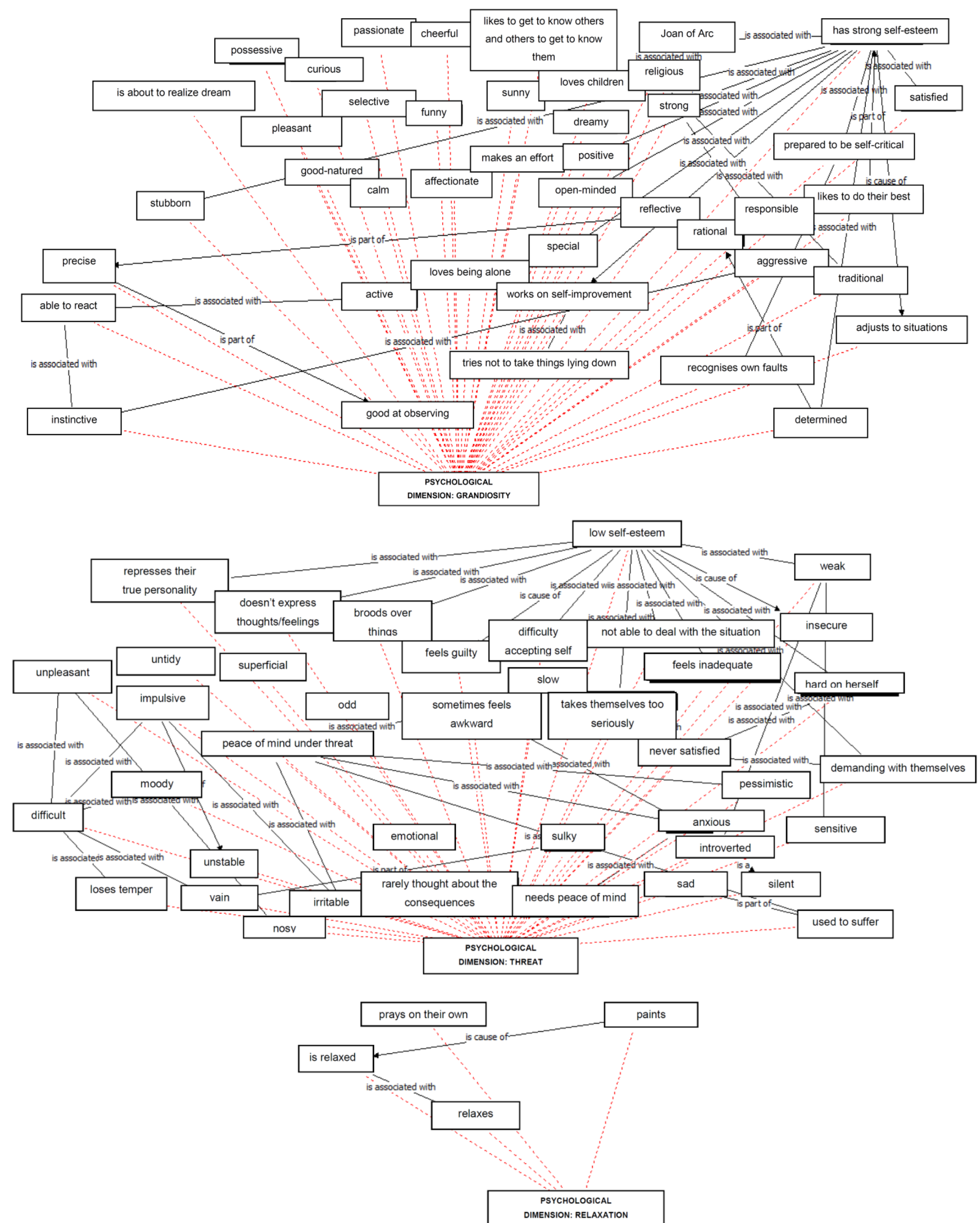

Fig. (2). Graphic representation of grandiose traits, threat and relaxation in the psychological dimension. 


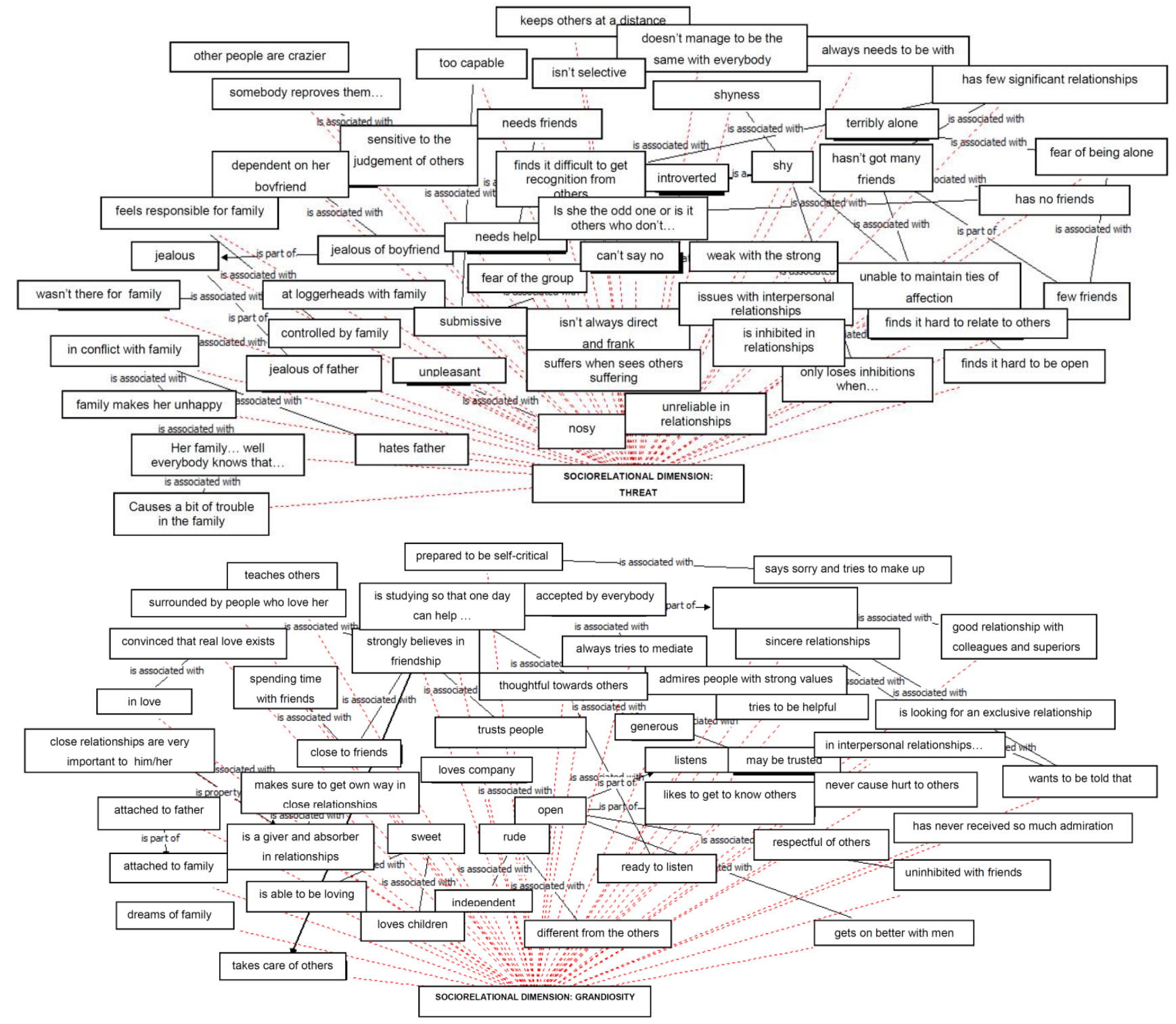

Fig. (3). Graphic representation of grandiose traits, threat and relaxation in the relational dimension.

\section{CONCLUSION}

The results appear to confirm our hypothesis regarding the key importance of the socio-relational dimension in relation to threat and grandiosity. This dimension also plays a key role in the domain of relaxation, although in this context bodily and physiological contents are equally present and salient.

At the clinical-interpretative level it would appear that the "public" (whether made up of one or more other persons) is of vital importance, both in situations of threats to selfesteem and in grandiosity [33, 14, 15]. In contrast, when subjects wish to relax they focus on fantasies that involve the physical-bodily and psychological dimensions rather than the relational one.

With regard to triadic/polyadic interactions, our results confirm that triadic contexts do not feature in people's "common sense" schemas [34]: subjects tend to think of interactions predominantly in dyadic terms. However it is interesting to note that the highest frequency of triadic/polyadic interactions occurs in relation to threats to self-esteem.

In sum, our findings provide further evidence for the structural similarities between the domains of grandiosity and threats to self-esteem hypothesized in the literature [3, $35,36]$. In contrast, relaxation appears to follow a pattern of its own. This suggests that narcissists' attempts to protect their self-esteem via grandiose manoeuvres only reinforce the very sense of threat and feelings of inadequacy from which they are desperately trying to protect themselves. A more effective distancing strategy could be to progressively train themselves to focus on whatever they find relaxing. It is most likely that narcissists seek "refuge" in grandiose fantasizing because they have difficulty protecting themselves from threats to their self-esteem by drawing on strategies that help them to relax [32].

Naturally some limitations of the present work should be noted. Firstly, while our findings provide useful guidance for 
the formulation of hypotheses to be extended to patient populations, they may not be reliably generalized in that the data was drawn from a non-clinical sample. The low numerosity of the sample, and the uneven gender distribution and young age of the participants, also prevents us from viewing the results as definitive. Nevertheless, it must be noted that in the qualitative research samples must be large enough to provide a set of data to explain the phenomenon we want to study, but at the same time if the sample is too large data becomes redundant and superfluous. Summing up in this study the authors followed the principle of saturation [37]; that is when new data are not able to add any further explanation on the research's questions under investigation.

\section{CONFLICT OF INTEREST}

The authors confirm that this article content has no conflicts of interest.

\section{ACKNOWLEDGEMENTS}

Declared none.

\section{REFERENCES}

[1] American Psychiatric Assiociation. Diagnostic and statistical manual of mental disorders. $4^{\text {th }}$ ed. Washington DC: APA 2000.

[2] Dimaggio G, Fiore D, Salvatore G, Carcione A. Dialogical relationship patterns in narcissistic personalities: session analysis and treatment implications. J Construct Psych 2007; 20: 23-51.

[3] Horowitz MJ. Clinical phenomenology of narcissistic pathology. Psych Clin N Am1989; 12: 531-39.

[4] Bateman AW. Thick- and thin-skinned organisations and enactment in borderline and narcissistic disorders. Int J Psychoanal 1998; 79: 13-22.

[5] Bursten B. The relationship between narcissistic and antisocial personalities. In: Kernberg OF, Ed. Narcissistic personality disorder. Psychiatric Clinics of North America. Saunders: Philadelphia 1989; pp. 571-84.

[6] Dimaggio G, Fiore D, Lysaker PH, et al. Early narcissistic transference patterns: an exploratory single case study from the perspective of dialogical self theory. Psychol Psychother 2006; 79: 495-516.

[7] Kernberg OF. Borderline conditions and pathological narcissism. New York: American Psychiatric Press 1975.

[8] Kohut $\mathrm{H}$. The analysis of the self. New York: International University Press 1971.

[9] Kohut H. The restoration of the self. New York: International University Press 1977.

[10] Modell AH. Psychoanalysis in a new context. New York: International University Press 1984.

[11] Ryle A, Kerr I. Introducing cognitive analytic therapy. Principle and Practice. Chichester: Wiley 2002.

[12] Twenge JM, Campbell WK. Isn't it fun to get the respect that we're going to deserve? Narcissism, social rejection, and aggression. Pers Soc Psychol Bull 2003; 29: 261-72.

[13] Westen D. The relations among narcissism, egocentrism, selfconcept and self-esteem: experimental, clinical and theoretical considerations. Psychoan Contem Thought 1990; 13: 183-239.

[14] Dimaggio G, Semerari A. Ed. Personality disorders. Models and treatment. Bari: Laterza 2003.
[15] Dimaggio G, Semerari A, Falcone M, Nicolò G, Carcione A, Procacci M. Metacognition, states of mind, cognitive biases and interpersonal cycles. Proposal for an integrated model of Narcissism. J Psycho Int 2002; 4: 421-51.

[16] Veronese G, Ruggiero GM, Sassaroli S, Castiglioni M. Interpersonal and individual factors in the grandiose fantasies and threats to self-esteem of a non-clinical sample Open Psych J 2011; 4: $1-5$.

[17] Ruggiero GM, Veronese G, Castiglioni M, Sassaroli S. Grndiose fantasies and low self-esteem: an experimental study. Psychol Stud 2011; 56: 368-72.

[18] Bateson G. Steps to ecology of mind. London: Chandler Publishing Company 1972.

[19] Fivaz-Depeursinge E, Corboz-Warnery A, Keren M. The primary triangle. Treating infants in their families. In: Sameroff AJ, McDonough SC, Rosenblum KL, Eds. Treating parent-infant problems. Strategies for intervention. New York: Guilford Press 2004; pp. 123-51.

[20] Haley J. Changing Families: a family therapy reader. New York: Grune \& Stretton 1971.

[21] Schaffer HR. Child care in a changing society. In: Robertson A, Osborn A, Eds. Social Services and the quality of Life. London: Heinemann 1984.

[22] Ugazio V. Semantic polarities in the family. Permitted and forbidden stories. New York: Routledge 2013.

[23] Ugazio V, Castiglioni M. Socialization models and the construction of self. J construct Psych 1998; 11: 3-29.

[24] Veronese G, Castigliani M, Ruggiero G, Sassaroli S. Threath of self-esteem and grandios fantasies in non-pathological narcissism. Ricerca in Psicoterapia 2009, 12: 55-66.

[25] Campbell WK, Foster JD. In: The narcissistic self: background and extended agency model and ongoing controversies. Sedikides C, Spencer JS. New York: Psychology Press 2007; pp. 115-38.

[26] Safran JD, Muran JC. Negotiating the therapeutic alliance. New York: The Guilford Press 2000.

[27] Foster JD. Incorporating personality into the investment model: probing commitment processes across individual differences in narcissism. J Soc Pers Rel 2008; 25: 212-23.

[28] Foster JD, Shrira I, Campbell WK. Theoretical model of narcissism, sexuality, and relationship commitment. J Soc Pers Rel 2006; 23: 367-86.

[29] Kelly GA. The psychology of personal constructs. New York: Norton 1955

[30] Veronese G, Procaccia R, Romaioli D, Barola G, Castiglioni M. Psychopathological organizations and attachment styles in patients with fear of flying: a case study. Open Psych J 2013; 6: 20-27.

[31] Engel GL. The need for a new medical model: a challenge for biomedicine. Science 1977; 196: 129-36.

[32] Cascio CN, Konrath S, Falk EB. Narcissists' social pain seen only in the brain. Soc Cogn Affect Neurosci 2014. First published online: May 23, 2014. doi: 10.1093/scan/nsu072.

[33] Pincus AL, Cain NM, Wright AGC. Narcissistic grandiosity and narcissistic vulnerability in psychotherapy. First published online: Jan 20, 2014. doi: 10.1037/per0000031.

[34] Ugazio V, Fellin L, Pennacchio R, Negri A, Colciago F. Is systemic thinking really extraneous to common sense? J Fam 2012; 34: 53-71.

[35] Vater A, Ritter K, Schröder-Abé M, et al. When grandiosity and vulnerability collide: implicit and explicit self-esteem in patients with narcissistic personality disorder. J Beh Exp Psychi 2013; 44: $37-47$.

[36] Thomas J, Al Hasmi A, Chung MC, Morgan K, Lyons M. The narcissistic mask: an exploration of 'the defensive grandiosity hypothesis'. Pers Men Heal 2013; 7: 160-7

[37] Glaser B, Strauss A. The discovery of grounded theory: strategies for qualitative research. New York: Aldine Publishing Company 1967. 